\title{
EPISTEMOLOGIA NATURALIZADA: UMA ANÁLISE POPPERIANA DA PROPOSTA DE QUINE
}

\section{Naturalized Epistemology:A Popperian Analysis of Quine's proposal}

Paulo Eduardo de Oliveira ${ }^{1}$

\section{Resumo}

Este trabalho pretende apresentar a análise de Popper sobre a noção de "epistemologia naturalizada " proposta por Quine .O ponto central dessa discussão é a posição de Popper em relação àquilo que Quine denomina "aspectos doutrinais " da epistemologia, ou seja, a preocupação com 0 problema da verdade e da certeza. Para Popper, em virtude da sua proposta epistemológica de uma incessante busca da verdade, apenas estes aspectos interessam, uma vez que não têm sentido as discussões acerca dos "aspectos conceituais".

Palavras-chave: epistemologia naturalizada, racionalismo crítico, verdade e certeza.

\section{Abstract}

This work intends to present the Popper's analysis about the notion of " naturalized epistemology" proposed by Quine.The central point of discussion is the Popper's position related to what Quine denominates "doctrinal aspects " of epistemology,or somehow the concem with theproblem of truth and certainty.For Popper,because of his epistemological proposal of the uncceasing search for truth, only these aspects are important,once there is no meaning in these discussions about the "conceptual aspects ".

Keywords: Naturalized epistemology,critica rationalism,truth and certainty.

1 Doutor em Filosofia pela PUCSP, Professor do Programa de Pós-Graduação em Filosofia da PUCPR.

Rua Imaculada Conceição, 1155 - Prado Velho - CEP 80.215-901 - Tel. (41) 271-2241

- Curitiba - PR - Brasil

E-mail: paulo.educardo@pucpr.br

Revista de Filosofia, Curitiba, v. 16 n.18, p. 149-158, jan./jun. 2004. 


\section{Introdução}

O presente trabalho objetiva mostrar, ainda que de modo propedêutico, as linhas de uma discussão crítica das posições de Quine a partir de alguns pontos da filosofia de Popper no que tange à compreensão da epistemologia, sobretudo sob o rótulo "epistemologia naturalizada". Como ponto de partida da discussão, escolhemos dois textos: Epistemologia Naturalizada, de Quine, que corresponde ao capítulo 3 de Relatividade Ontológica e Outros Ensaios $(1969)^{2}$, e, de outro lado, o trabalho de Popper intitulado Uma visão realista da Lógica, da Física e da História, texto baseado no Discurso de Abertura do Primeiro Colóquio Internacional realizado na Universidade de Denver, em maio de 1966, e publicado em Conhecimento Objetivo (1972) ${ }^{3}$, além de referências menores a outros textos de Karl Popper.

\section{A compreensão de Quine quanto à noção de epistemologia naturalizada}

No texto relativamente breve em que Quine apresenta o que entende por naturalização da epistemologia, o filósofo, logo de início, afirma: "A epistemologia se interessa pelos fundamentos da ciência. Concebida com essa amplitude, a epistemologia incluiu o estudo dos fundamentos da matemática como um de seus ramos ${ }^{\prime 4}$. Esse é seu ponto de partida e, disso, deriva toda a argumentação por ele construída para explicitar a noção de epistemologia naturalizada.

Para isso, Quine especifica os dois principais aspectos do estudo dos fundamentos da matemática, a saber, o conceitual e o doutrinal. Para ele, o primeiro se refere ao significado, isto é, à clareza dos conceitos; o segundo, por sua vez, refere-se à verdade, ou seja, ao estabelecimento de leis e princípios. A inclusão do estudo dos fundamentos da matemática no âmbito da epistemologia parece ter, para Quine, uma razão modelar ou paradigmática: o que ocorre com a matemática pode ocorrer, por uma espécie de espelhamento, com os outros campos da

2 QUINE, Willard. Relatividade Ontológica e outros ensaios. Coleção Os Pensadores, São Paulo: Nova Cultural, 1989.

3 POPPER, Karl. Conhecimento Objetivo. São Paulo/Belo Horizonte: EDUSP/Itatiaia, 1975.

4 QUINE, W. op. cit, p. 91.

Revista de Filosofia, Curitiba, v. 16 n.18, p. 149-158, jan./jun. 2004. 
ciência. É o próprio Quine quem afirma: "Idealmente, os conceitos mais obscuros seriam definidos em termos dos mais claros, de modo a maximizar a clareza, e as leis menos óbvias seriam provadas a partir das mais óbvias, de modo a maximizar a certeza" ${ }^{\prime 5}$. Trata-se, assim, de um processo que implica simplificação, clareamento, explicitação conceitual e teorética (ou axiomática). É curioso notar que Quine usa a expressão "idealmente", pois compreende que a realização desse propósito se mostra, ao menos no campo da matemática, como uma tarefa de elevado grau de dificuldade, embora possa ser considerada de modo hipotético.

Embora os dois ideais, o aumento da clareza conceitual e 0 aumento da certeza doutrinal, sejam aspectos distintos, Quine mostra que ambos estão, de certa forma, interligados: "Se em particular os conceitos matemáticos fossem todos redutíveis aos termos claros da lógica, todas as verdades da matemática passariam a ser verdades da lógica”6. A redução se daria, ao mesmo tempo, tanto em relação ao significado dos conceitos quanto em relação à verdade das leis e princípios, ou seja, ela contemplaria os dois ramos da bifurcação proposta: o conceitual e 0 doutrinal. Note-se o uso da partícula condicional "se" e o futuro do pretérito como tempo verbal escolhido por Quine para se referir a esta possibilidade. Isso evidencia, outra vez, o caráter hipotético e conjectural dessa pretensão, pois a matemática não pode ser reduzida à lógica propriamente dita, senão à lógica e à teoria dos conjuntos e, conforme mostrou a obra de Göedel, e isto Quine reconhece, nenhum sistema axiomático consistente pode cobrir a matemática. Portanto, conclui Quine: "A redução dentro dos fundamentos da matemática continua a ser fascinante do ponto de vista matemático e filosófico, mas não realiza 0 sonho do epistemólogo: não revela o fundamento do conhecimento matemático, não mostra como a certeza matemática é possível ${ }^{\prime 7}$. O caso modelar mostra, assim, de pronto, os próprios limites. Mas Quine não está preocupado, aqui, com o problema da matemática e, sim, com o da fundamentação da epistemologia. Apesar da impossibilidade de realizar as pretensões sugeridas no âmbito da matemática, Quine afirma que ainda resta uma "sugestão" para a epistemologia: ele se refere à bifurcação entre teoria dos conceitos (ou dos significados) e teoria da doutrina (ou da verdade): “Assim como a matemática é redutível à lógica, ou a

5 QUINE, W. op. cit, p. 91.

QUINE, W. op. cit, p. 91.

7 QUINE, W. op. cit, p. 92.

Revista de Filosofia, Curitiba, v. 16 n.18, p. 149-158, jan./jun. 2004. 
lógica e teoria dos conjuntos, assim o conhecimento natural será baseado, de algum modo, na experiência sensível. Isso significa explicar a noção de corpo em termos sensoriais; eis o aspecto conceitual. E significa justificar o nosso conhecimento de verdades da natureza também em termos sensoriais; eis o aspecto doutrinal da bifurcação"8. Em outras palavras, trata-se de 'traduzir' um conceito e uma teoria (admitida como verdadeira) em termos sensoriais, isto é, reduzindo-os ao tratamento empírico, ou material, ou físico.

Esse parece ser o credo da epistemologia naturalizada e, ao mesmo tempo, sua regula vitae. Para Quine, grandes esforços foram feitos para realizar esse ideal, sobretudo por Hume, Carnap e o próprio Círculo de Viena, mas a conclusão negativa a que todos chegaram é de que é impossível deduzir as verdades da natureza a partir da evidência sensorial. Qual é o resultado desse fracasso teórico? Para Quine, é o abandono da esperança de tudo traduzir (ou reduzir, o que parece ser a mesma coisa) para termos observacionais e lógico-matemáticos. Para alguns filósofos isso pode parecer o fim da epistemologia, como, de fato, pareceu, conforme afirma Quine: "Carnap e os outros positivistas lógicos do Círculo de Viena já haviam dado ao termo 'metafísica' uma carga pejorativa, a de um termo que conota ausência de significado; e o termo 'epistemologia' era o próximo. Wittgenstein e seus seguidores, principalmente em Oxford, descobriram uma vocação filosófica residual na terapia: em curar filósofos da ilusão de que há problemas epistemológicos" ${ }^{\prime 9}$. Eis uma primeira sugestão de clínica filosófica aplicada aos próprios filósofos.

O que nos resta, então? E essa é a posição de Quine no texto em pauta: “... a epistemologia continua a avançar, ainda, embora num novo quadro e com um status clarificado. A epistemologia, ou algo que a ela se assemelhe, encontra seu lugar simplesmente como um capítulo da psicologia e, portanto, da ciência natural"10. Note-se que o 'status clarificado' significa, somente, um 'lugar reduzido', e assim nem mais importa se estamos tratando da epistemologia ou de 'algo que a ela se assemelhe'. Ela é apenas um capítulo num campo específico da ciência natural. Quine ainda afirma: "A antiga epistemologia aspirava a conter

\footnotetext{
8 QUINE, W. op. cit, p. 92.

9 QUINE, W. op. cit, p. 98.

10 QUINE, W. op. cit, p. 98.
} 
em si, num certo sentido, a ciência natural; ela se constituiria, de algum modo, a partir dos sense data. No seu novo quadro, inversamente, a epistemologia está contida na ciência natural..."11. Eis o veredicto de Quine.

\section{Aproximações a uma análise popperiana do problema}

É importante lembrarmos o ponto de partida escolhido por Quine, em relação ao qual Popper assume uma posição muito bem definida. Quine distinguiu, no estudo dos fundamentos da matemática, os aspectos conceituais dos aspectos doutrinais. Ora, para Popper, e esse é um aspecto muito importante de sua filosofia, não interessam os aspectos conceituais. Em muitas ocasiões Popper afirma: "Nunca discuto sobre palavras"12. Essa sua posição fica ainda mais clara quando o filósofo afirma que seu critério de demarcação científica não é um critério de significado $^{13}$. A intenção de Popper é, em primeiro lugar, estabelecer o limite entre sua filosofia e as posições dos positivistas lógicos do Círculo de Viena ${ }^{14}$. Em segundo lugar, explicitar sua atitude em relação à filosofia de Wittgenstein ${ }^{15}$.

Porém, embora os aspectos conceituais da bifurcação proposta por Quine não sejam considerados por Popper, a ele interessam os aspectos doutrinais, ou seja, aqueles que dizem respeito à verdade e à certeza. Para Popper, o objetivo de todo empreendimento científico (e, assim, de toda a epistemologia) é a inacabada busca da verdade ${ }^{16}$.

11 QUINE, W. op. cit, p. 98-99.

12 POPPER, K. En busca de un mundo mejor. Barcelona: Paidós, 1994, p. 120.

13 POPPER, K. A Lógica da Pesquisa Científica. São Paulo: Cultrix, 1974, capítulo 1, nota (*3), p. 42: "Note-se bem que eu apresento o critério de falseabilidade como critério de demarcação, mas não como critério de significado" (o itálico é do próprio autor).

${ }_{14}$ Cf. POPPER, K. A Lógica da Pesquisa Científica, p. 545, in: Prefácio da segunda edição alemã: "Eu procurava, pelo menos em parte, traçar uma linha divisória entre minhas concepções e as que eram sustentadas pelos adeptos do positivismo, reunidos no 'Círculo de Viena' ".

15 Cf. POPPER, K. A Lógica da Pesquisa Científica, p. 37-38, onde Popper afirma que se contrapõe ao estratagema antimetafísico de Wittgenstein.

16 Cf. POPPER, K. Conjecturas e Refutações. Brasília: UnB, 1994, especialmente o capítulo 10, p. 241ss: "Verdade, Racionalidade e Expansão do Conhecimento".

Revista de Filosofia, Curitiba, v. 16 n.18, p. 149-158, jan./jun. 2004. 
Quanto ao problema específico proposto por Quine, qual é a posição de Popper? Em primeiro lugar, ele admite a possibilidade de 'redução', não apenas da matemática à lógica (com todas as dificuldades que isso implica), mas também entre outros campos da ciência, apesar de negar os aspectos conceituais de tal empreendimento. Nesse sentido, Popper afirma: "A física e a química não são muito diferentes e não parece haver grande diferença no tipo de coisas a que se aplicam (...) Não seria, portanto, muito surpreendente se as esperanças, há longo tempo mantidas, de que a química possa ser reduzida à física, vierem a tornar-se verdadeiras, como de fato parecem estar se tornando. Aqui temos o caso real de uma 'redução'; e por uma redução quero sem dúvida dizer que todas as descobertas da química podem ser plenamente explicadas pelos (isto é, deduzidas dos) princípios da física”17. Nota-se, de imediato, que Popper nem sequer considera a questão conceitual da redução e, em seu texto, a palavra redução aparece duas vezes em itálico, ou seja, Popper parece não estar nada preocupado com o que possa significar a palavra redução, mas o que lhe interessa é como ela se aplica, de fato, à ciência e qual é o resultado disso em termos de explicação do mundo e de aproximação à verdade. Para Popper, a redução mostra-se possível e até desejável enquanto é entendida como um expediente prático que significa a dedução das descobertas de um campo da ciência a partir dos princípios ou das leis (e não dos conceitos) de outro campo. E o filósofo continua: "Embora tal redução não fosse muito surpreendente, seria um êxito científico muito grande. Não só seria um exercício de unificação, mas um real avanço na compreensão do mundo"18. Vejam que Popper se refere à redução, quase com ironia, como sendo um 'exercício de unificação'. Ora, para Popper, não importa muito a que campo de saber se referem as descobertas, pois a própria demarcação dos limites de um saber e de outro, ou de uma ciência e de outra, são insignificantes. Com efeito, Popper afirma: "Quando ansiamos por saber, quando o nosso objetivo é aprender algo acerca do mundo, não nos preocupamos muito com os compartimentos ou departamentos que possam ser atribuídos ao que virá a ser o nosso conhecimento"19 $^{\prime 2}$ Mas, se há uma importância na redução, ela reside no

17 POPPER, K. Conhecimento Objetivo. São Paulo/Belo Horizonte: Edusp/Itatiaia, 1975, p. 266. Daqui para a frente, vamos nos referir a esta obra indicando apenas o autor e 0 título.

18 POPPER, K. Conhecimento Objetivo, p. 266.

${ }_{19}$ POPPER, K. O realismo e o objectivo da ciência. Pós-Escrito à Lógica da Pesquisa Científica, vol. I: Lisboa: Dom Quixote, 1992, p. 177.Cf. ainda A Lógica da Pesquisa Científica, p. 57. 
avanço real de nossa compreensão do mundo ou, em outros termos, ainda popperianos, ela se refere à busca da verdade. Nada mais. Por essa razão, Popper diz: "Redução (...) significa compreensão teórica; a penetração teórica do novo campo pelo campo antigo"20. E sua ironia sutil não deixa de se manifestar: “... aqueles crentes na redução que, por alguma razão filosófica ou outra, adotam a priori a posição dogmática de que a redução deve ser possível, de certo modo destroem seu triunfo se um dia a redução for realizada. Pois o que então será realizado deveria ter sido realizado todo tempo"21.

Embora Popper aceite, ainda que em seus próprios termos, a possibilidade de redução, ele contesta a posição de Quine no que tange à redução de nossos relatos (ou teorias) mentais a eventos físicos. Popper afirma: "Quine diz, com referência a Carnap e a Feigl, que, se o progresso teórico pode ser 'realizado por... postular estados mentais distintos... por trás de comportamento físico, certamente o mesmo tanto... pode ser realizado postulando-se... em vez disso certos estados e eventos fisiológicos correlatos... a falta de uma explicação fisiológica detalhada dos estados será escassa objeção a reconhecê-los como estados de corpos humanos... Os estados corporais existem de qualquer modo; por que acrescentar os outros?'22. Em contraposição a Quine, Popper afirma que ele não é um 'realista científico', pois não espera para ver se a ciência, um dia, vai ou não fazer aqui ou acolá alguma redução; ao contrário, Popper afirma, Quine indica que entidades mentais não são necessárias para a teoria.

A posição crítica de Popper em relação a Quine advém de sua admissão da existência, em separado, de estados mentais. Afirma, pois, 0 filósofo: "Se entidades mentais ou, melhor, estados mentais existissem - e eu próprio não duvido de que existam - então é necessário postular estados mentais para qualquer explicação verdadeira deles; e se eles um dia forem reduzidos a estados físicos, isto será um tremendo sucesso. Mas não haverá sucesso algum, em absoluto, se rejeitarmos sua existência notando simplesmente que podemos explicar todas as coisas sem eles, pelo método simples de nos confinarmos às coisas físicas e a seu comportamento"23.

20 POPPER, K. Conhecimento Objetivo, p. 267.

21 POPPER, K. Conhecimento Objetivo, p. 267.

22 POPPER, K. Conhecimento Objetivo, p. 268. Popper se refere ao texto de Quine Word and Object, 1960, p. 264.

23 POPPER, K. Conhecimento Objetivo, p. 268.

Revista de Filosofia, Curitiba, v. 16 n.18, p. 149-158, jan./jun. 2004. 
Para Popper, assim, a redução pode ser um caminho interessante desde que seja vista como teoria experimental, não simplesmente como propostas a serem adotadas para expressar tudo numa linguagem fisicista, como pretendem alguns filósofos positivistas. Tais propostas, afirma Popper "... têm muito a seu favor porque são indubitavelmente convenientes; problemas inconvenientes tais como o problema de corpo-mente na realidade desaparecem, muito convenientemente. Assim, esses fisicistas pensam que não pode haver dúvida de que esses problemas serão eliminados como pseudo-problemas"24.

Nesse ponto, Popper envereda para a compreensão mesma do problema da redução, evitando a solução lingüística ao problema, ou seja, o "método demasiado simples de recusar a falar"25 de certos problemas. Para enfrentar, então, o problema levantado, Popper faz a distinção entre dois tipos de redução: a primeira, que ele chama de 'boa redução', ou científica, é aquela onde se aprende muito sobre o campo a ser reduzido (a química, no exemplo anterior) e se aprende muito, ainda, a respeito das forças da teoria redutora (a física, naquele mesmo exemplo); ao contrário, a 'redução má', ou redução ad hoc, é a que se processa por métodos meramente lingüísticos, como propõe o fisicismo que exige a explicação de postulados fisiológicos para explicar um fenômeno que já se explicou postulando estados mentais.

A posição de Popper fica mais clara quando compreendemos a sua 'teoria dos três mundos' ${ }^{26}$. Esse parece ser o ponto crucial em que Popper e Quine divergem. Para Popper, o 'mundo um' corresponde ao mundo das realidades físicas e de todos os fenômenos empíricos; o 'mundo dois' corresponde aos nossos estados ou processos mentais, independente das reações fisiológicas de que derivam (tais reações fazem parte do 'mundo um'); finalmente, o 'mundo três' corresponde aos produtos da mente (idéias, teorias, livros, esta nossa conversa). Na concepção popperiana, essa visão tripartida da realidade é fundamental para a solução adequada do problema da redução, uma vez que permite entender a relação corpo e mente, ou seja, a distinção entre estados físicos ou fisiológicos ('mundo um') e estados mentais ('mundo dois'). A vantagem

${ }^{24}$ POPPER, K. Conhecimento Objetivo, p. 269.

${ }^{25}$ POPPER, K. Conhecimento Objetivo, p. 269.

${ }^{26}$ POPPER, K. Conhecimento Objetivo, p. 108, capítulo 3: "Epistemologia sem um sujeito conhecedor" e p. 151, capítulo 4: "Sobre a teoria da mente objetiva". 
principal dessa concepção é a possibilidade de, por ela, distinguirmos relações de causalidade e relações lógicas dos fenômenos e dos produtos da mente, respectivamente: "Assim, temos de fato estes dois mundos diferentes, o mundo de processos de pensamento e o mundo dos produtos de processos de pensamento. Enquanto o primeiro pode permanecer em relações causais, o último permanece em relações lógicas"27. Aqui fica evidente, outra vez, a preocupação de Popper com o aspecto doutrinal da bifurcação inicialmente proposta por Quine. Popper acredita que o conteúdo do 'mundo três' é o que pode, realmente, entrar no jogo da disputa pela verdade, por meio da possibilidade de crítica que ele apresenta: “Entre os habitantes de meu 'terceiro mundo' há, mais especialmente, sistemas teóricos; mas habitantes de igual modo importantes são problemas e situações de problema. E argumentarei que os moradores mais importantes desse mundo são argumentos críticos e o que pode ser chamado - em analogia a um estado material ou a um estado de consciência - o estado de uma discussão ou o estado de um argumento crítico; e, naturalmente, os conteúdos de revistas, livros e bibliotecas"28.

Nesse sentido, a afirmação de Quine de que a epistemologia pode ser reduzida a um capítulo da psicologia não resolve o problema da busca dos fundamentos da epistemologia, pois a psicologia trata apenas de um aspecto, a saber, o mundo dos processos mentais, o 'mundo dois'. Mas, a epistemologia, ao contrário, deve se ocupar, sobretudo, dos produtos mentais, ou seja, do 'mundo três'. Quine quer justificar a epistemologia detendo-se num 'mundo' onde ela não reside.

Para concluir: a posição popperiana frente à 'redução' visa, exclusivamente, o aumento do conhecimento e, com isso, a aproximação à verdade. $O$ aspecto conceitual de uma possível 'redução' não é a questão fundamental. O problema de base reside, em suma, na compreensão da relação corpo-mente-teoria, ou seja, na compreensão das imbricações existentes entre o mundo dos fatos, o mundo dos processos mentais e 0 mundo dos produtos mentais. Nessa perspectiva, a redução da epistemologia à psicologia é, sem dúvida, sua redução à teoria empirista do conhecimento.

27 POPPER, K. Conhecimento Objetivo, p. 273-274.

28 POPPER, K. Conhecimento Objetivo, p. 109.

Revista de Filosofia, Curitiba, v. 16 n.18, p. 149-158, jan./jun. 2004. 
Referências

POPPER,K. A Lógica da Pesquisa Científica. São Paulo: Cutrix, 1974. POPPER, K. Conjecturas e Refutações. Brasília: UnB, 1994.

Recebido em/ Receieved in: 24/05/2004 Aprovado em/Approved in : 27/07/2004 